\title{
Total immunoreactive proinsulin, immunoreactive insulin and specific insulin in relation to conversion to NIDDM: the Mexico City Diabetes Study
}

\author{
S.M . H affner ${ }^{1}$, C . G onzalez ${ }^{2}$, L. M ykkänenn ${ }^{1}$, M . Stern ${ }^{1}$ \\ ${ }^{1}$ Department of Medicine, University of Texas Health Science Center at San Antonio, San Antonio, Texas, USA \\ ${ }^{2}$ Centro de Estudios en Diabetes, American British Cowdray Hospital and Endocrinology and Metabolism Service, Division of \\ Internal Medicine, Specialty Hospital of the National Medical Center, Mexican Social Security Institute, Mexico City, Mexico
}

Summary Although insulin resistance and decreased insulin secretion are characteristic of established non-insulin-dependent diabetes mellitus (NIDDM), which of these metabolic abnormalities is the primary determinant of NIDDM is still controversial. A disproportionate increase in the proinsulin to insulin ratio has been proposed as a marker of compromised insulin secretion. We examined the association of fasting immunoreactive insulin (which cross-reacts with proinsulin), specific insulin (which does not cross-react with proinsulin), total immunoreactive proinsulin (or insulin precursors), and the fasting proinsulin/specific insulin ratio to the risk of developing NIDDM in the 3.25-year follow-up of the Mexico City Diabetes Study. These measurements were made in 85 subjects who subsequently converted to NIDDM (prediabetic subjects) and in 85 age and gender matched subjects who remained non-diabetic at follow-up (control subjects). Immunoreactive insulin, proinsulin and the proinsulin/specific insulin ratio were significantly higher in prediabetic than in control subjects. However, the relation between specific insulin and the development of NIDDM was weaker than for proinsulin or immunoreactive insulin. After further adjustment for obesity, body fat distribution and glucose tolerance status, proinsulin and the proinsulin/specific insulin ratio, but not specific or immunoreactive insulin, predicted conversion to NIDDM. A high proinsulin/specific insulin ratio predicted conversion to NIDDM both in subjects with normal and those with impaired glucose tolerance at baseline. We conclude that in prediabetic subjects increased proinsulin, a marker of islet cell distress or compromised insulin secretion, is associated with rapid conversion (within 3.25 years) to NIDDM even in obese populations. [Diabetologia (1997) 40: 830-837]

Keywords Insulin, proinsulin, insulin secretion, noninsulin-dependent diabetes mellitus.
Non-insulin-dependent diabetes mellitus (NIDDM) is characterized by peripheral insulin resistance, beta-cell failure, and increased hepatic glucose

Received: 29 November 1996 and in revised form: 12 March 1997

Corresponding author: S. Haffner M. D., Department of Medicine, University of Texas Health Science Center at San Antonio, 7703 Floyd Curl Drive, San Antonio, TX 78284-7873, USA

A bbreviations: NIDDM, Non-insulin-dependent diabetes mellitus; IGT, impaired glucose tolerance; CI, confidence interval; AIR, acute insulin response; RIA, radioimmunoassay; WHR, waist-hip ratio. production [1]. In diabetic subjects, these metabolic abnormalities interact in a complex fashion to cause and sustain hyperglycaemia. However, there continues to be controversy about which of these abnormalities is primary. Both insulin resistance [2] and deficient insulin secretion [3] have been postulated as antecedents of NIDDM. Prospective studies are useful in elucidating the complex relationship between abnormal insulin secretion and peripheral insulin resistance in the pathogenesis of NIDDM.

Previous prospective studies have shown that hyperinsulinaemia is a strong predictor of NIDDM [411]. Insulin resistance has been inferred on the basis of hyperinsulinaemia in these studies of prediabetic subjects; in non-diabetic subjects, there is a 
moderately good correlation between insulin resistance and fasting insulin concentration $(r=-0.6)$ [12-14], although these correlations may be slightly weaker in subjects with impaired glucose tolerance (IGT) $[13,14]$. Insulin resistance as measured by the hyperinsulinaemic, euglycaemic clamp [15] or the frequently sampled intravenous glucose tolerance test [16] also predicts the development of NIDDM. Several studies have suggested that impaired insulin secretion as assessed by a low acute insulin response to intravenous glucose (AIR), a low increment of insulin to glucose ratio over $30 \mathrm{~min}$ on an oral glucose tolerance test or a low 2-h insulin post oral glucose load [9-11, 15, 17-19] also predicts the development of NIDDM. In one study, however, insulin secretion did not predict the development of NIDDM in children of diabetic parents [16]. The majority of the studies which showed that compromised insulin secretion predicts the development of NIDDM were performed in subjects with IGT $[4,9,18,19]$ in whom impaired insulin secretion is typically present $[20,21]$.

Recently, there has been increasing recognition that conventional immunoreactive assays for insulin cross-react with proinsulin. Proinsulin is disproportionately elevated in subjects with NIDDM [3, 2227]. The ratio of fasting proinsulin to fasting insulin, however, is only minimally elevated in normal subjects or subjects with IGT in some studies [23, 28], and not at all in others [27]. Several recent studies have suggested that increased fasting proinsulin concentrations and the ratio of fasting proinsulin/fasting insulin predict the development of NIDDM [29-31]. These studies clearly indicated that in subjects who had IGT at baseline [29, 31] fasting proinsulin predicted the development of NIDDM. These studies, however, tended to have too few subjects who converted to NIDDM to separately examine whether elevated proinsulin predicts conversion to NIDDM equally well in those with normal glucose tolerance (NGT) as in those with IGT at baseline. In the present study, we examined the ability of proinsulin, fasting specific insulin (which does not cross-react with proinsulin) and fasting immunoreactive insulin to predict conversion to NIDDM in the Mexico City Diabetes Study. Mexicans residing in Mexico City are a high-risk population for NIDDM and are relatively obese compared to non-Hispanic whites living in the United States [32].

\section{Subjects and methods}

In Mexico City, six low-income neighbourhoods (colonias) were selected for the study $[32,33]$. Complete enumerations of these colonias were carried out from February 1990 to October 1992 and 3326 study eligible individuals [35-64-year-old men and non-pregnant women) were identified. Of these 2813 $(84.5 \%)$ completed a home interview and 2278 completed a medical examination at a clinic (response rate $=68.5 \%$ ).
Subjects who attended the clinic examination were similar to those who provided a home interview only, in terms of age, gender, and self-reported history of myocardial infarction, diabetes and cigarette smoking. The protocol was approved by the institutional review board of the University of Texas Health Science Center at San Antonio and all subjects gave informed consent.

In April 1993, we began a 3.25-year follow-up to determine the incidence of NIDDM [34]. The response rate to the followup examination was $77.6 \%$. Ninety-seven out of the 1449 initially non-diabetic subjects who attended the follow-up examination had converted to NIDDM. Subjects who attended the follow-up examination were similar to those who did not attend the follow-up examination in terms of age, gender and self-reported diabetes, myocardial infarction and cigarette smoking. Identical methods were used at both the baseline and the follow-up of the survey. Forty-four out of 198 subjects $(22.2 \%)$ with IGT developed NIDDM and 53 of $1251(4.2 \%)$ of subjects with NGT developed NIDDM after 3.25 years.

Height, weight, waist and hip circumference were measured using previously described methods [35]. The ratio of the waist-to-hip circumference (WHR) was used as a measure of body fat distribution. Body mass index (BMI) (weight/ height $\left.{ }^{2}\right)\left(\mathrm{kg} / \mathrm{m}^{2}\right)$ was used as a measure of overall adiposity. At baseline and follow-up (3.25 years), blood specimens were obtained after a 12- to 14-h fast for determination of serum insulin and plasma glucose concentrations. Glucose and insulin concentrations were also measured $2 \mathrm{~h}$ after a standardized 75-g oral glucose load. Plasma insulin was measured by a solid phase radioimmunoassay that shows a relatively high degree of cross-reactivity with insulin precursors [22, 23, 36].

In the subset of subjects reported on in this paper, we also measured baseline insulin by a specific antibody as well as baseline proinsulin. The specific insulin measurement was accomplished by specific double antibody radioimmunoassay (RIA) (human specific RIA method, Linco, St. Louis, Mo., USA) that displays less than $0.2 \%$ cross-reactivity with insulin precursors [37]. The insulin-specific measurement is performed according to the kit instructions at room temperature as an overnight equilibrium RIA. Specificity for true insulin is achieved by use of an insulin antibody that reacts with the free $\mathrm{NH}_{2}$-terminal of the A-chain of insulin. Intact human proinsulin and des 31,32 human proinsulin are not reactive in this assay because the required epitope is blocked by the lysine/ arginine dibasic linkage connecting insulin with C-peptide. Cross-reactivity with intact and des 31,32 proinsulin (the major circulating form of split proinsulin) has been determined to be $0.2 \%$ and less than $0.2 \%$, respectively [37]. The cross-reactivity of the insulin assay with des 64,65 proinsulin is much higher $(\sim 76 \%)$, but des 64,65 proinsulin comprises less than $5 \%$ of total circulating insulin precursors [38]. Within- and between-assay coefficients of variation of the specific insulin assay ranged from 3 to $7 \%$. The midpoint of the assay is $46 \pm 6$ $\mathrm{pmol} / \mathrm{l}$ when a $100-\mu \mathrm{l}$ sample volume is used. The lower limit of detection of the assay was $14.4 \mathrm{pmol} / \mathrm{l}$.

Insulin precursors were measured by a non-equilibrium RIA method [38]. This method was modified slightly to improve the sensitivity at low concentrations of proinsulin. Antibody was obtained from Linco Research. The polyclonal antibody used in this assay (168AB) recognizes a proinsulin specific epitope formed by the intact A-chain-C-peptide junction. In this assay, the potency of human insulin and C-peptide is less than $0.1 \%$ that of proinsulin. Under non-equilibrium conditions, A-chain-C-peptide junction cleaved forms of proinsulin are less than $1 \%$ as potent as intact proinsulin, whereas Bchain-C-peptide junctional cleaved forms, such as des 31,32 proinsulin have a cross-reactivity greater than $95 \%$. Because des 31,32 is the major circulating form of split proinsulin 
(approximately 95\%), the proinsulin RIA method reported here provides an estimate of the total immunoreactive proinsulin concentration (intact proinsulin + B-C-junctional cleaved forms) in plasma. Since the term 'total immunoreactive proinsulin' is unwieldy, for simplicity we will refer to this entity as 'proinsulin' throughout the remainder of the paper. The intraassay coefficient of variation ranged from 6 to $21 \%$ using controls prepared at 5,50 and $250 \mathrm{pmol} / 1$ [23]. The lower limit of detection of the proinsulin assay is $2.0 \mathrm{pmol} / \mathrm{l}$.

IGT and diabetes were classified at baseline and follow-up according to World Health Organization criteria [39]. Subjects who gave a history of diabetes and who at the time of their clinic examination were taking either insulin or oral antidiabetic agents were also considered to have diabetes regardless of their plasma glucose values. Diabetic subjects who were not taking insulin were considered to have NIDDM. Insulin-taking diabetic subjects whose age of onset was more than 40 years or whose BMI was greater than $30 \mathrm{~kg} / \mathrm{m}^{2}$ were also considered to have NIDDM. The remaining insulin-taking diabetic subjects were considered to have insulin-dependent diabetes or to be unclassifiable and were excluded from the analyses. In Mexico, the serum was stored in a $-70^{\circ} \mathrm{C}$ freezer until being shipped to San Antonio in dry ice at approximately 4- to 6-week intervals. Shipments arrived in San Antonio within $48 \mathrm{~h}$ of being sent. Although certain measurements were also made in Mexico City for clinical purposes (e.g. glucose and cholesterol), all study measurements were made in San Antonio in the Division of Clinical Epidemiology laboratory. Since this report is concerned with the metabolic precursors of NIDDM, subjects with diabetes at baseline are excluded.

We identified 85 initially non-diabetic subjects who subsequently converted to NIDDM and in whom baseline fasting serum contingency samples were available. We matched subjects who did not convert to NIDDM to those who did by gender and age ( \pm 2 years). (Initially 97 control subjects were matched to 97 cases. However, contingency samples were not available on 12 cases and 2 control subjects). Thus we had 85 incident diabetic subjects who could be matched to 85 subjects who were non-diabetic at both baseline and follow-up. The average duration of storage of contingency specimens was 54 months for both cases and control subjects. Samples had not been thawed prior to the analyses for proinsulin and specific insulin.

Statistical analysis. Statistical analysis was performed using the SAS statistical software. Analyses included analyses of covariance (Table 1), chi-squared test (Table 1), conditional multiple logistic regression (Fig. 1 and 2 and Table 2 ) and unconditional (ordinary) multiple logistic regression (Table 3). In multiple logistic regression analyses, the development of NIDDM was the dependent variable. In Table 2, stepwise conditional multiple logistic regression analyses was used. Statistical analyses included testing for interaction terms in multiple logistic regression analyses to determine whether the effect of metabolic variables was similar in subjects with NGT and IGT (Table 3) and in obese and non-obese subjects; in each case, the interaction term was not statistically significant suggesting that the effect of metabolic variables was similar in the various subpopulations. Multiple logistic regression analyses was performed with the key independent variables (insulin, proinsulin and proinsulin/insulin ratio) as both continuous and categorical variables (quartiles). In analyses which used continuous variables, insulin and proinsulin were log transformed to improve skewness and kurtosis and were back transformed for presentation in the Tables. Analyses using continuous and categorical independent variables yielded similar results. Categorical variables based on quartiles were coded as $0,1,2$, and 3 for statistical testing. Only analyses based on categorical data are shown
Table 1. Baseline clinical characteristics of subject by conversion status to NIDDM at follow-up: Mexico City Diabetes Study

\begin{tabular}{llll}
\hline & Converters & $\begin{array}{l}\text { Control } \\
\text { subjects }\end{array}$ & p-value \\
\hline $\mathrm{n}$ & 85 & 85 & \\
IGT at baseline $(\mathrm{n})$ & 45 & 12 & $<0.001$ \\
Age (years) & $47.4 \pm 7.3$ & $46.6 \pm 7.9$ & 0.450 \\
Gender $(\%$ male) & $39 \%$ & $39 \%$ & 0.985 \\
Body mass index (kg/m²) & $30.3 \pm 5.2$ & $27.8 \pm 3.8$ & $<0.001$ \\
Waist-to-hip ratio & $0.98 \pm 0.06$ & $0.97 \pm 0.07$ & 0.130 \\
Fasting insulin (pmol/l) & & & \\
$\quad$ Specific & $92.1 \pm 1.7$ & $79.7 \pm 1.8$ & 0.076 \\
$\quad$ Immunoreactive & $120 \pm 12.0$ & $73.2 \pm 12.7$ & 0.002 \\
Fasting proinsulin (pmol/l) & $16.4 \pm 21$ & $10.9 \pm 1.8$ & $<0.001$ \\
Proinsulin/specific insulin & $0.23 \pm 0.16$ & $0.15 \pm 0.08$ & $<0.001$ \\
Fasting glucose (mmol/l) & $5.37 \pm 0.09$ & $4.68 \pm 0.06$ & $<0.001$ \\
2-h glucose (mmol/l) & $7.55 \pm 0.23$ & $5.65 \pm 0.17$ & $<0.001$ \\
\hline Data are mean $\pm \mathrm{SE}$ & & & \\
\hline
\end{tabular}

Data are mean $\pm \mathrm{SE}$

Table 2. Multiple logistic regression analyses ${ }^{\text {a }}$ for the development of NIDDM

\begin{tabular}{llll}
\hline Variable & Odds ratio & $\begin{array}{l}\text { 95\% confidence } \\
\text { interval }\end{array}$ & p-value \\
\hline $\begin{array}{l}\text { Proinsulin/specific } \\
\text { insulin }\end{array}$ & 3.51 & $1.68,7.36$ & $<0.001$ \\
$\begin{array}{l}\text { Impaired glucose } \\
\text { tolerance (yes/no) }\end{array}$ & 7.94 & $3.25,19.2$ & $<0.001$ \\
Body mass index & 2.01 & $1.02,3.97$ & 0.041 \\
Specific insulin & 1.58 & $0.72,3.48$ & 0.258 \\
Waist-to-hip ratio & 1.05 & $0.496,2.20$ & 0.909 \\
\hline
\end{tabular}

Variables are shown in the order of entry

Odds ratios for the following variables were calculated for values above vs below the median (median value given in parenthesis):

Proinsulin/specific insulin (0.15)

Body mass index $\left(28.6 \mathrm{~kg} / \mathrm{m}^{2}\right)$

Specific insulin $(85.8 \mathrm{pmol} / \mathrm{l})$

Waist-to-hip ratio (0.978 in men and 0.862 in women)

${ }^{\mathrm{a}}$ conditional logistic analyses

in Figures 1 and 2, since they are easier to interpret (i.e. not necessary to present log transformed variables) and since they reveal a dose response (or lack of it) more effectively. We also substituted waist circumference for BMI and WHR in multiple logistic regression models similar to those presented in Table 3; the results for the key metabolic variables (proinsulin/insulin ratio and specific insulin) were similar and thus only BMI and WHR are shown in Table 2. Since we used a matched case control design, we used both a conditional logistic analyses (for the matched design) and logistic regression (not incorporating the matched pair design). The conditional logistic regression analyses utilized 85 cases and 85 control subjects. Since both approaches yielded similar results we present the conditional logistic regression in most situations. However, in the stratified analyses using glucose tolerance and obesity status, we used the unconditional analyses since the conditional logistic regression analyses would require us to omit pairs in which one subject had IGT and the other subjects had NGT or 


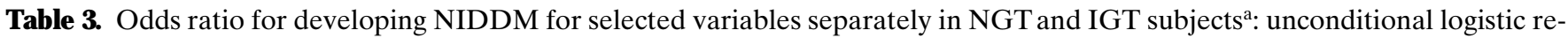
gression analyses

\begin{tabular}{|c|c|c|c|c|c|c|}
\hline \multirow[t]{2}{*}{ Variable } & \multicolumn{3}{|l|}{ NGT } & \multicolumn{3}{|l|}{ IGT } \\
\hline & OR & $95 \% \mathrm{CI}$ & $p$-value & OR & $95 \% \mathrm{CI}$ & $p$-value \\
\hline \multicolumn{7}{|c|}{ Specific insulin } \\
\hline low & 1.00 & - & - & 1.00 & - & - \\
\hline high & 1.56 & $0.74,3.29$ & 0.240 & 3.91 & $2.41,6.33$ & $<0.001$ \\
\hline \multicolumn{7}{|c|}{ I mmunoreactive insulin } \\
\hline low & 1.00 & - & - & 1.00 & - & - \\
\hline low & 1.00 & - & - & 1.00 & - & - \\
\hline high & 2.22 & $1.04,4.76$ & 0.040 & 3.98 & $2.38,6.53$ & $<0.001$ \\
\hline \multicolumn{7}{|c|}{ Proinsulin/specific insulin } \\
\hline low & 1.00 & - & - & 1.00 & - & - \\
\hline high & 4.20 & $1.89,9.32$ & $<0.001$ & 3.93 & $2.57,7.01$ & $<0.001$ \\
\hline
\end{tabular}

OR, Odds ratio; CI, confidence interval; NGT, normal glucose tolerance; IGT, impaired glucose tolerance

${ }^{a}$ Unconditional logistic regression adjusted for age and gender

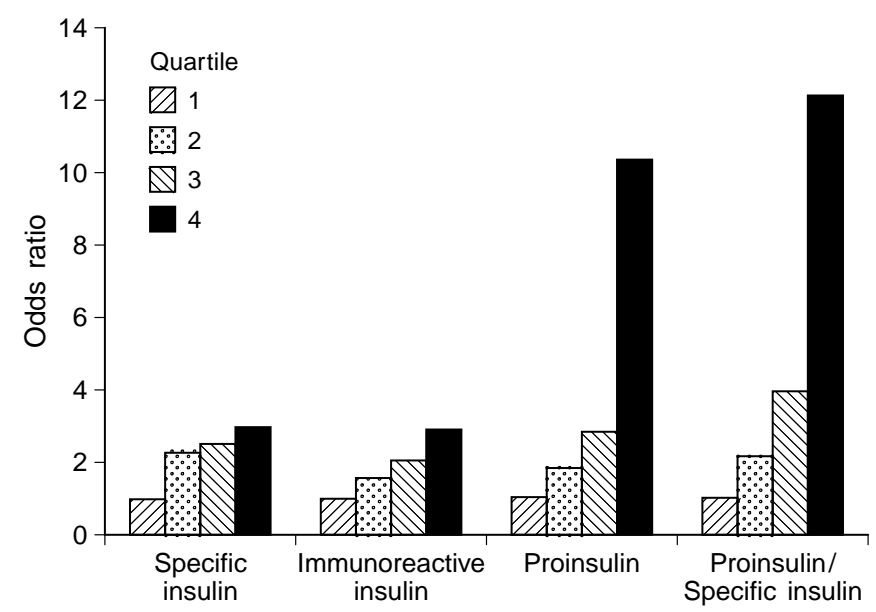

Fig. 1. Risk of developing NIDDM as assessed by multiple logistic regression by quartiles of fasting specific insulin (pmol/ 1): (quartile 1: <55.8; quartile 2: 55.8 to 85.8 ; quartile $3: 85.8$ to 122.4; and quartile $4: \geq 122.4), p=0.087$; fasting immunoreactive insulin (pmol/l): (quartile 1: $<60.0$; quartile 2: 60.0 to 81.2; quartile 3: 81.2 to 122 ; quartile $4: \geq 122$ ), $p=0.009$; fasting proinsulin (pmol/1): (quartile 1: $<8.3$; quartile 2: 8.3 to 12.7 ; quartile $3: 12.7$ to 20.2 ; and quartile $4: \geq 20.4), p=0.002$; fasting proinsulin/fasting specific insulin: (quartile $1:<0.112$; quartile 2: 0.112 to 0.152 ; quartile $3: 0.152$ to 0.233 ; and quartile $4: \geq 0.233), p<0.001$

alternatively one subject was lean and the other was obese thereby sacrificing statistical power. Age and gender were controlled for in the unconditional logistic regression but were not adjusted for in the conditional logistic regression (in which case and controls were matched for age and gender). Obesity was defined as a BMI above the median for the population (greater than $29.0 \mathrm{~kg} / \mathrm{m}^{2}$ ).

\section{Results}

Table 1 shows the baseline clinical and metabolic characteristics of subjects by follow-up status. Age and gender were matched and therefore similar in cases and control subjects. Subjects who converted to NIDDM had significantly higher BMI, immunoreactive insulin, proinsulin and proinsulin to specific insulin ratio. Subjects who converted to NIDDM were more likely to have IGT at baseline than subjects who did not convert to NIDDM. Subjects who converted to NIDDM also had moderately higher specific insulin than non-converters, although this difference was only of borderline statistical significance $(p=0.078)$. WHR did not differ by conversion status.

Figure 1 shows the risk of developing NIDDM by quartiles of metabolic variables using conditional logistic regression analyses. For fasting immunoreactive insulin, fasting proinsulin and proinsulin/specific insulin, there is a stepwise increase in risk of NIDDM. However, for fasting specific insulin, subjects in the lowest quartile were at the lowest risk of developing NIDDM with a relatively flat response for higher levels of specific insulin. These results were statistically significant for fasting proinsulin $(p<0.001)$, fasting proinsulin/fasting insulin ratio $(p<0.001)$ and fasting immunoreactive insulin $(\mathrm{p}=0.008)$, but not for fasting specific insulin $(p=0.081)$.

Table 2 shows the results of a stepwise conditional multiple logistic regression analyses with the development of NIDDM as the dependent variable and BMI, WHR, glucose tolerance status, specific insulin and proinsulin/specific insulin as independent variables. Variables are shown in the order of entry. The proinsulin/insulin ratio entered first followed by IGT. IGT $(\mathrm{OR}=7.94,95 \%$ confidence interval $(\mathrm{CI})=3.25,19.2)$, proinsulin/specific insulin ratio $(\mathrm{OR}=3.51,95 \% \mathrm{CI}=1.68,7.36)$ and $\mathrm{BMI}$ significantly predicted the development of NIDDM. Specific insulin was associated with an increased risk of NIDDM but this result was not statistically significant $(\mathrm{OR}=1.58,95 \% \mathrm{CI}=0.72,3.48)$. WHR was not significantly related to the risk of NIDDM. We also fit similar multiple logistic regression models in 


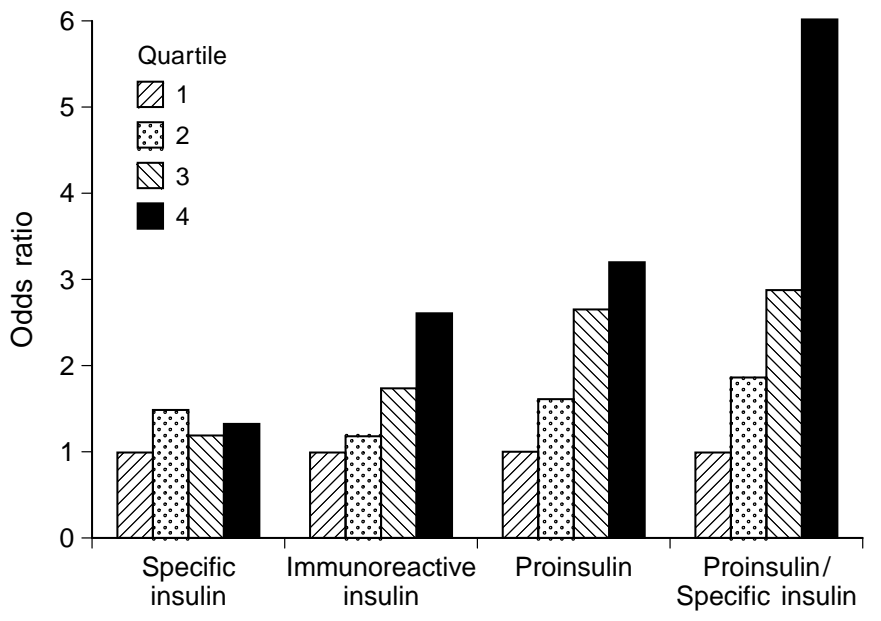

Fig. 2. Risk of developing NIDDM as assessed by multiple logistic regression (adjusted for body mass index, waist-to-hip ratio and glucose tolerance status) by quartiles of fasting specific insulin (pmol/1): (quartile $1:<55.8$; quartile 2: 55.8 to 85.8 ; quartile 3 : 85.8 to 122.4 ; and quartile $4: \geq 122.4), p=0.280$; fasting immunoreactive insulin (pmol/l): (quartile $1:<60.0$; quartile 2 : 60.0 to 81.2 ; quartile $3: 81.2$ to 122 ; quartile $4: \geq 122$ ), $\mathrm{p}=0.085$; fasting proinsulin ( $\mathrm{pmol} / \mathrm{l})$ : (quartile $1:<8.3$; quartile $2: 8.3$ to 12.7 ; quartile $3: 12.7$ to 20.2 ; and quartile $4: \geq 20.4), p=0.001)$; fasting proinsulin/fasting specific insulin: (quartile 1: $<0.112$; quartile 2: 0.112 to 0.152 ; quartile $3: 0.152$ to 0.233 ; and quartile $4: \geq 0.233), p<0.001$

which proinsulin and specific insulin were modelled separately (rather than as a ratio as in Table 2). Proinsulin, but not specific insulin, predicted the development of NIDDM (data not shown). We also fit similar multiple logistic regression models in which proinsulin and immunoreactive insulin were modelled separately. Both proinsulin and immunoreactive insulin significantly predicted the development of NIDDM (data not shown).

Figure 2 shows the risk of developing NIDDM by quartiles of metabolic variables, adjusted for BMI, WHR, and glucose tolerance status. Rising fasting immunoreactive insulin, fasting proinsulin and proinsulin/specific insulin ratio were associated with a stepwise increase in the risk of developing NIDDM, although was statistically significant only for proinsulin and proinsulin/insulin ratio. After adjustment for the additional variables in Figure 2, fasting specific insulin was not significantly related to the risk of NIDDM. We also performed logistic regression analysis adjusting for 2-h glucose rather than glucose tolerance (IGT vs NGT). These results were similar to those presented in Figure 2 ( $p=0.001$ for proinsulin and $p<0.001$ for proinsulin/specific insulin). Similar results were observed in analyses performed separately in men and women (data not shown) $(p<0.05)$.

We next estimated the risk of developing NIDDM separately in subjects with NGT and IGT at baseline. Table 3 shows these analyses adjusted for age and gender using unconditional logistic regression analyses.
In subjects with NGT at baseline, fasting proinsulin and the proinsulin/insulin ratio significantly predicted the development of NIDDM. However, specific insulin and immunoreactive insulin did not significantly predict the development of NIDDM. In IGT subjects, fasting specific and immunoreactive insulin, as well as fasting proinsulin and the proinsulin/ specific insulin all predicted the development of NIDDM. We also fit interaction terms for glucose tolerance status $($ IGT vs NGT) $\times$ metabolic factors $($ e.g. proinsulin) using multiple logistic regression analyses. In none of the four regression models were the interaction terms statistically significant $(p>0.20)$ suggesting that the effect of metabolic risk factors was similar in subjects with IGT or NGT at baseline and that the lack of significance for certain risk factors (e. g. insulin) for developing diabetes in NGT subjects might be due to lack of statistical power.

We also computed the risk of development of NIDDM separately in less obese (BMI $<29.0 \mathrm{~kg} / \mathrm{m}^{2}$ ) and more obese $\left(\geq 29.0 \mathrm{~kg} / \mathrm{m}^{2}\right)$ subjects. (The cutoffpoint of $29.0 \mathrm{~kg} / \mathrm{m}^{2}$ represents the median BMI in this population.) Higher proinsulin and proinsulin/ specific insulin significantly predicted the development of NIDDM both in more and less obese subjects (data not shown).

\section{Discussion}

We have shown in this report that increased fasting proinsulin concentrations as well as an elevated proinsulin/insulin ratio predict the development of NIDDM within 3.25 years. Our data are consistent with earlier studies in which elevated proinsulin concentrations predicted conversion to NIDDM in subjects with IGT $[29,31]$ or in the overall population [30]. In a preliminary report, Berne et al. [40] showed that increased proinsulin split products predicted the development of NIDDM in a Swedish cohort. In our study, the ratio of proinsulin/insulin and the absolute concentration of proinsulin predicted the development of NIDDM, even after adjustment for BMI, WHR and glucose tolerance status at baseline (Table 2).

Saad et al. [41] have proposed a two-step model for the development of NIDDM. Increased insulin resistance is most important in the early stages during the transition from NGT to IGT while decreased insulin secretion is most important in the later stages, i.e. the transition from IGT to NIDDM. In the subgroup analyses (Table 3) we showed that compromised insulin secretion (as assessed by a high proinsulin and high ratio of proinsulin/insulin) predicted conversion to NIDDM in subjects with IGT at baseline. Similarly, Kahn et al. [29], and Nijpels et al. [31] also showed that increased proinsulin/specific insulin ratio predicted conversion to NIDDM in subjects with 
IGT at baseline. Mykkänen et al. [30] did not stratify their data by glucose tolerance status at baseline. Compromised beta-cell function, as assessed by a variety of other methods (AIR, early insulin increment in response to oral glucose load or 2-h insulin), has been shown to predict NIDDM in IGT subjects in several studies $[9,18,19]$. Few data are available on whether decreased insulin secretion predicts the development of NIDDM in subjects with NGT. This is because the conversion rate to NIDDM is much lower in subjects with NGT than in subjects with IGT, and thus the number of converters in most studies is low and the statistical power limited. In the current report, we identified 85 subjects who converted to NIDDM of which 40 had NGT at baseline. In these latter individuals, a high proinsulin/insulin ratio and high absolute levels of proinsulin both predicted conversion to NIDDM suggesting that compromised insulin secretion predicts conversion to NIDDM even in subjects whose glucose levels are normal. It should be noted, however, that despite their NGT these subjects could still be regarded as being in the late stages of the prediabetic process since, like the subjects with IGT, they converted within 3.5 years.

There are several possible explanations for the increased proinsulin to insulin ratios in prediabetic subjects. In the normal beta cell, the conversion of proinsulin to insulin is very efficient; whereas in prediabetic subjects, an intracellular abnormality may reduce the conversion of proinsulin to insulin leading to a disproportionately increased proinsulin to insulin ratio [42]. The conversion of proinsulin to insulin occurs within the beta-cell secretory granule [43]. The increased release of proinsulin from the secretory granule could result from an innate defect in the secretory granule or alternatively, early release of proinsulin before its conversion to insulin is complete. Rhodes and Alarcon [44] have suggested that the beta-cell defect is worsened by the increased stress placed on the beta-cell by hyperglycaemia [44]. Another explanation for the higher proinsulin levels is that there is defective feedback inhibition of proinsulin secretion by insulin in prediabetic subjects [45].

Increased proinsulin levels are believed to represent a relative deficiency of insulin secretion or 'overly stressed' beta cell [3]. Increased proinsulin levels correlated with decreased insulin secretion [3]. Interestingly, while proinsulin, specific insulin and immunoreactive insulin levels were significantly associated with decreased insulin sensitivity (as determined by the frequently sampled intravenous glucose tolerance test] in 135 normoglycaemic subjects, the proinsulin/ specific insulin ratio was not, thereby reinforcing the belief that an increased proinsulin/insulin ratio is a marker for compromised insulin secretion rather than of decreased insulin sensitivity [46].

In this study, we also found a significant relation between immunoreactive insulin and the development of NIDDM (Table 2 and Fig. 1) $(p<0.01$, test for trend). However, the relation between specific insulin (which does not cross-react with proinsulin) and the development of NIDDM appeared to be much weaker. These results are consistent with other studies in which immunoreactive insulin predicted the development of NIDDM while specific insulin did not [30]. In the Japanese-American study [29] neither specific nor immunoreactive insulin predicted the development of NIDDM, although, elevated C-peptide level did. Lastly, in the Hoorn study [31], specific insulin did not predict the development of NIDDM; an assay for immunoreactive insulin was not reported in that study. The above reports suggests that the use of an insulin assay that recognizes proinsulin to assess conversion to NIDDM may overestimate the strength of the association between insulin and the imminent development of NIDDM (i.e. NIDDM that develops after a short follow-up period). It is possible that in studies of longer term conversion to NIDDM (7-10 years), fasting hyperinsulinaemia (implying insulin resistance) may be a stronger predictor of conversion. Insulin concentrations are often used in epidemiological studies as a surrogate for insulin resistance; in non-diabetic subjects, insulin resistance and fasting insulin levels are moderately well correlated [12-14].

In the present study, we used only a single oral glucose tolerance test which is typical of epidemiologic studies (with the exception of the Hoorn study [31]). The increased risk of misclassification associated with a single glucose tolerance test would tend to bias our results towards the null hypothesis. Thus, the true results could be even stronger.

After adjustment for obesity, body fat distribution and glucose tolerance, the relation between immunoreactive insulin and the development of NIDDM was only of borderline statistical significance. We believe that this non-statistically significant result could be due to a lack of statistical power associated with the present case control design, since when we analysed these data using the entire cohort, fasting immunoreactive insulin did significantly predict the development of NIDDM, even after adjustment for these same covariates [34].

An alternative possibility for the relatively greater predictive power of the immunoreactive insulin than of the specific insulin could be the greater reliability of the former assay. However, we do not believe this to be the case because both of these assays were evaluated in the American Diabetes Association standardization project [22] and had similar performance characteristics.

In conclusion, we have shown that prediabetic subjects even in obese, high-risk populations are characterized by abnormalities of insulin secretion. These results are only slightly attenuated by adjustment for obesity, an unfavourable body fat distribution and 
glucose intolerance and are similar both in subjects with NGT and IGT at baseline. Increased insulin concentrations (especially specific insulin which does not cross-react with proinsulin) were much weaker predictors of NIDDM in this study of short-term conversion to NIDDM.

A cknowledgements. This work was supported by a grant from the National Heart, Lung and Blood Institute (R01 HL24799).

\section{References}

1. DeFronzo RA (1988) The triumvirate: $\beta$-cell, muscle, liver: collusion responsible for NIDDM. Diabetes 37: 667-687

2. Reaven GM, Bernstein R, Davis B, Olefsky JM (1976) Non-ketotic diabetes mellitus: insulin deficiency or insulin resistance. Am J Med 60: 80-88

3. Porte D (1991) $\beta$-cells in type II diabetes mellitus. Diabetes 40: $166-180$

4. Sicree RA, Zimmett PZ, King HOM, Coventry JS (1987) Plasma insulin response among Nauruans: prediction of deterioration in glucose tolerance over 6 years. Diabetes 36: 179-186

5. Haffner SM, Stern MP, Mitchell BD, Hazuda HP, Patterson JK (1990) Incidence of type II diabetes in Mexican Americans predicted by fasting insulin and glucose levels, obesity and body fat distribution. Diabetes 39: 283-288

6. Bergstrom RW, Newell-Morris LL, Leonetti DL, Shuman WP, Wahl PW, Fujimoto WY (1990) Association of elevated fasting C-peptide level and increased intra-abdominal fat distribution with development of NIDDM in Japanese American men. Diabetes 39: 104-111

7. Charles MA, Fontbonne A, Thibult N, Warnet JM, Rosselin GE, Eschwege R (1991) Risk factors for NIDDM in white population: Paris prospective study. Diabetes 40: 796-799

8. Mykkänen L, Kuusisto J, Pyörälä K, Laakso M (1993) Cardiovascular disease risk factors as predictors of type 2 (non-insulin-dependent) diabetes mellitus in elderly subjects. Diabetologia 36: 553-559

9. Saad MF, Knowler WC, Pettitt DJ, Nelson RG, Mott DM, Bennett PH (1988) The natural history of impaired glucose tolerance in the Pima Indians. N Engl J Med 319: 15001506

10. Lundgren H, Bengtsson C, Blohme G, Lapidus L, Waldenström J (1990) Fasting serum insulin concentration and early insulin response as risk determinants for developing diabetes. Diabet Med 7: 407-413

11. Haffner SM, Miettinen H, Gaskill SP, Stern MP (1995) Decreased insulin secretion and increased insulin resistance are independently related to the 7-year risk of non-insulin dependent diabetes mellitus. Diabetes 44: 1386-1391

12. Hollenbeck CB, Chen N, Chen YDI, Reaven GM (1984) Relationship between the plasma insulin response to oral glucose and insulin stimulated glucose utilization in normal subjects. Diabetes 33: 460-463

13. Saad MF, Anderson RL, Laws A, et al. for the Insulin Resistance Atherosclerosis Study (1994) Comparison between the minimal model and the glucose clamp in the assessment of insulin sensitivity across the spectrum of glucose tolerance. Diabetes 43: 1114-1121

14. Laakso M (1993) How good a marker is insulin level for insulin resistance? Am J Epidemiol 137: 959-965

15. Lillioja S, Mott DM, Spraul M et al. (1993) Insulin resistance and insulin secretory dysfunction as precursors of non-insulin-dependent diabetes mellitus: prospective studies of Pima Indians. N Engl J Med 329:1988-1992

16. Warram JH, Martin BC, Krolewski AS, Soeldner JS, Kahn CR (1990) Slow glucose removal rate and hyperinsulinemia precede the development of type II diabetes in the offspring of diabetic parents. Ann Intern Med 113: 903-915

17. Efendic S, Luft R, Wajngot A (1984) Aspects of the pathogenesis of type 2 diabetes. Endocr Rev 5: 395-410

18. Kosaka K, Hagura R, Kuzuya T (1977) Insulin responses in equivocal and definite diabetes with special reference to subjects who had mild glucose intolerance but later developed definite diabetes. Diabetes 26: 944-952

19. Kadowaki T, Miyake Y, Hagura R et al. (1984) Risk factors for worsening to diabetes in subjects with impaired glucose tolerance. Diabetologia 26: 44-49

20. Watanabe RM, Laws A, Rewers M, Bergman RN for the IRAS investigators (1995) Impaired glucose tolerant subjects exhibit a $\beta$-cell defect despite normal fasting glycemia. Diabetes 44[Suppl 1]:5A (Abstract)

21. Mitrakou A, Kelley D, Mokan M et al. (1992) Role of reduced suppression of glucose production and diminished early insulin release in impaired glucose tolerance. $\mathrm{N}$ Engl J Med 326: 22-29

22. Robbins DC, Andersen L, Bowsher R et al. (1996) Task Force Report. Report of the American Diabetes Associations Task Force on standardization of the insulin assay. Diabetes 45: 242-256

23. Haffner SM, Bowsher RR, Mykkänen L et al. (1994) Proinsulin and specific insulin concentration in high and low risk populations for NIDDM. Diabetes 43: 1490-1493

24. Temple RC, Carrington CA, Luzio SD et al. (1989) Insulin deficiency in non-insulin-dependent diabetes. Lancet I:293-295

25. Reaven GM, Chen YDI, Hollenbeck CB, Shen WHH, Ostrega D, Polonsky KS (1993) Plasma insulin, C-peptide and proinsulin concentrations in obese and non-obese individuals with varying degrees of glucose tolerance. J Clin Endocrinol Metab 76: 44-48

26. Yoshioka N, Kuzuya T, Matsuda A, Taniguchi M, Iwamoto Y (1988) Serum proinsulin levels at fasting and after oral glucose load in patients with type 2 (non-insulin-dependent) diabetes mellitus. Diabetologia 31: 355-360

27. Saad MF, Kahn SE, Nelson RG et al. (1990) Disproportionately elevated proinsulin in Pima Indians with non-insulin-dependent diabetes mellitus. J Clin Endocrinol Metab 70: 1247-1253

28. Davies M, Metcalfe J, Gray IP, Day JL, Hales CN (1993) Insulin deficiency and increased plasma concentrations of intact and 32/33 split proinsulin in subjects with impaired glucose tolerance. Diabet Med 10: 313-320

29. Kahn SE, Leonetti DL, Prigeon RL, Boyko EJ, Bergstrom RW, Fujimoto WY (1995) Proinsulin as a marker for the development of NIDDM in Japanese American men. Diabetes 44: 173-179

30. Mykkänen L, Haffner SM, Kuusisto J, Pyöräla, Hales CN, Laakso M (1995) Serum proinsulin levels are disproportionately increased in elderly prediabetic subjects. Diabetologia 38: 1176-1182

31. Nijpels G, Popp-Snijders C, Kostense PJ, Bouter LM, Heine RJ (1996) Fasting proinsulin and 2-h post glucose levels predict the conversion to NIDDM in subjects with impaired glucose tolerance: the Hoorn Study. Diabetologia 39: $113-118$

32. Stern MP, Gonzalez C, Mitchell BD, Villalpando E, Haffner SM, Hazuda HP (1992) Genetic and environmental determinants of type II diabetes in Mexico City and San Antonio. Diabetes 41: 484-492 
33. González C, Stern MP, Mitchell BD, Valdez R, Haffner SM, Pérez BA (1994) Clinical characteristics of type II diabetic subjects consuming high vs low carbohydrate diets in Mexico City and San Antonio, TX. Diabetes Care 17: 397404

34. Haffner SM, Gonzalez C, Miettinen H, Kennedy E, Stern MP (1996) A prospective analysis of the HOMA model. Diabetes Care 19: 1138-1141

35. Haffner SM, Stern MP, Hazuda HP, Pugh JA, Patterson JK, Malina R (1986) Upper body and centralized adiposity in Mexican Americans and non-Hispanic whites: relationship to body mass index and other behavioral and demographic variables. Int J Obes 10: 493-502

36. Haffner SM, Stern MP, Hazuda HP, Pugh J, Patterson J (1986) Hyperinsulinemia in a population at high risk for non-insulin dependent diabetes mellitus. N Engl J Med 315: 220-224

37. Haffner SM, Stern MP, Miettinen H, Gingerich R, Bowsher RR (1995) Higher proinsulin and specific insulin are both associated with a parental history of diabetes in non-diabetic Mexican American subjects. Diabetes 44: 1156-1160

38. Bowsher RR, Wolny JD, Frank BH (1992) A rapid and sensitive radioimmunoassay for the measurement of proinsulin in human serum. Diabetes 41: 1084-1090
39. World Health Organization Study Group on Diabetes Mellitus (1985) Diabetes Mellitus: Report of a WHO Study Group. Geneva, World Health Organization, pp.94-98 (Tech. Rep. Ser. No.727)

40. Berne C, Lithell H, Clark PMS, Hales CN (1994) Split proinsulin is an early marker of non-insulin dependent diabetes mellitus. Diabetologia 37[Suppl 1]:A57 (Abstract)

41. Saad MF, Knowler WC, Pettitt DJ et al. (1991) A two-step model for development of non-insulin-dependent diabetes. Am J Med 90: 229-235

42. Porte D Jr, Kahn SE (1989) Hyperproinsulinemia and amyloid in NIDDM: clues to etiology of islet $\beta$-cell dysfunction? Diabetes 38: 1333-1336

43. Halban PA (1991) Structural domains and molecular lifestyles of insulin and its precursors in the pancreatic beta cell. Diabetologia 34: 767-778

44. Rhodes CJ, Alarcón C (1994) What $\beta$-cell defect could lead to hyperproinsulinemia in NIDDM? Diabetes 43: 511-517

45. Wasada T, Kuroki H, Arii H et al. (1994) Physiological increase in plasma insulin concentration suppresses proinsulin secretion in normal controls but not in subjects with glucose intolerance. Endocrine J 41: 183-188

46. Mykkänen L, Haffner SM, Hales CN, Rönnemaa T, Laakso $M$ (1997) The relation of proinsulin, insulin and proinsulinto-insulin ratio to insulin sensitivity and acute insulin response in normoglycemic subjects. Diabetes (in press) 